\title{
Immune Modulation in Asthma: Current Concepts and Future Strategies
}

\author{
Marek Lommatzsch \\ Abteilung für Pneumologie/Interdisziplinäre Internistische Intensivstation, Medizinische Klinik I, \\ Zentrum für Innere Medizin, Universitätsmedizin Rostock, Rostock, Germany
}

\section{Keywords}

Asthma - Immune modulation · Allergen immunotherapy · Oral corticosteroids

\begin{abstract}
Asthma treatment concepts have profoundly changed over the last 20 years, from standard therapeutic regimens for all patients with asthma towards individually tailored interventions targeting treatable traits ("precision medicine"). A precise and highly effective immune modulation with minimal adverse effects plays a central role in this new concept. Recently, there have been major advances in the treatment of asthma with immune-modulatory compounds. One example is the approval of several highly potent biologics for the treatment of severe asthma. New immune-modulatory strategies are expected to enter clinical practice in the future; these innovations will be especially important for patients with treatment-resistant asthma. @ 2020 The Author(s)

Published by S. Karger AG, Basel
\end{abstract}

\section{Introduction}

Asthma is a very heterogeneous disease which is characterized by variable airflow limitation, a variable intensity and pattern of airway inflammation, and variable forms of airway hyperresponsiveness [1]. There are two main forms of asthma. Early-onset asthma starts during childhood or adolescence and is often associated with allergies and/or allergic diseases (such as allergic rhinitis and atopic dermatitis). Adult-onset asthma starts in adulthood, often lacks any association with allergies, and can be accompanied by the occurrence of chronic rhinosinusitis with nasal polyps (CRSwNP) [2]. The prevalence of asthma increased in the 20th century, and has now reached a mean prevalence of nearly $5 \%$ worldwide $[3,4]$. Until the beginning of the 20th century, medical treatment options for asthma were very limited. Smoking of so-called asthma cigarettes (made from the leaves of thorn apple which contain the anticholinergic scopolamine), ingestion of various formulations of theophylline, caffeine, or ephedrine, or inhalation of adrenaline were the only available pharmacologic compounds for asthma treatment [5]. None of these compounds were primarily aiming at immune modulation. Indeed, the concept that asthma is driven by chronic airway inflammation emerged only at the beginning of the 20th century [6]. The oldest form of immune modulation in asthma, allergen immunotherapy (AIT), was first described in 1911 [7] and initially developed for patients with allergic rhinitis and conjunctivitis; it took nearly 100 years until the advent of AIT options specifically designed for the treatment of allergic asthma [8]. In order to understand
C 2020 The Author(s)

Published by S. Karger AG, Basel

This is an Open Access article licensed under the Creative Commons Attribution-NonCommercial-4.0 International License (CC BY-NC) (http://www.karger.com/Services/OpenAccessLicense), applicable to the online version of the article only. Usage and distribution for commercial purposes requires written permission.
Prof. Dr. Marek Lommatzsch

Abteilung für Pneumologie/Interdisziplinäre Internistische Intensivstation Medizinische Klinik I, Zentrum für Innere Medizin, Universitätsmedizin Rostock Ernst-Heydemann-Strase 6, DE-18057 Rostock (Germany) marek.lommatzsch@med.uni-rostock.de 
Asthma pharmacology: milestones

\begin{tabular}{|c|c|}
\hline Introduction & Class of drugs \\
\hline $1950 s$ & Oral corticosteroids (OCS) \\
\hline 1960s & Short-acting beta-agonists (SABA) \\
\hline 1970s/1980s & Inhaled corticosteroids (ICS) \\
\hline \multirow[t]{2}{*}{ 1990s } & $\begin{array}{l}\text { Fixed combinations of ICS plus } \\
\text { long-acting beta-agonists (LABA) }\end{array}$ \\
\hline & Leukotriene receptor antagonists (LTRA) \\
\hline Since 2005 & Biologics \\
\hline Since 2014 & Long-acting muscarinic antagonists (LAMA) \\
\hline
\end{tabular}

Fig. 1. History of asthma pharmacology. Drug classes that are currently used in asthma therapy are shown, and the decade or year of their first approval.

current and future options of immune modulation in asthma, it is helpful to recall milestones of asthma pharmacotherapy in the 20th and 21 st century.

\section{History of Asthma Pharmacology}

There have been several milestones in the development of medications for asthma over the last 70 years (Fig. 1):

- In the 1950s, systemic glucocorticoids (administered intravenously, orally, or intramuscularly) became available for the treatment of asthma [9]. Treatment with oral corticosteroids (OCS) such as prednisolone led to rapid and massive improvements in asthma control and lung function. However, long-term OCS therapy is associated with severe adverse effects, such as overweight, osteoporosis, infections, diabetes, depression, and cardiovascular diseases [10-12]: this "collateral damage" dampened the enthusiasm for OCS significantly.

- In the 1960s, inhaled short-acting beta-2 agonists (SABA) such as salbutamol became available [13]. For the first time, this treatment option allowed for rapid and convenient bronchodilatation in case of asthma attacks, and led to the concept of "reliever" therapy in asthma. The popularity of these drugs rose rapidly, however, safety concerns emerged due to excess mortality in patients using regular SABA therapy [14]. This paradoxical increase in mortality is probably due to an increase in airway hyperresponsiveness and airway in- flammation following monotherapy with beta-agonists $[15,16]$. Therefore, monotherapies with longacting beta-agonists (LABA; such a formoterol or salmeterol) are not recommended in current asthma guidelines. In addition, the most recent guideline of the global initiative for obstructive lung diseases (GINA, 2019) does not recommend symptom-driven SABA treatment as the treatment of choice for mild asthma anymore (www.ginasthma.com).

- In the 1970s and 1980s, thanks to the pioneering studies by Harry Morrow Brown [17], inhaled corticosteroids (ICS) became available for asthma treatment. The ICS Beclomethasone was approved as the first ICS in the late 1970s, and was followed by other ICS, such as budesonide, fluticasone, and ciclesonide. Regular ICS therapy, which led to a massive decrease in asthma exacerbations and OCS prescriptions, revolutionized the management of asthma [18]. This success led to the concept of "controller" therapies in asthma, and to the idea that long-term immune modulation might be the best idea to improve asthma control [19]. Indeed, recent analyses showed that ICS are even effective in very mild forms of the disease [20]. Later, fixed combinations of ICS and LABA were approved for asthma maintenance therapy. These ICS/LABA combinations are not only more effective than ICS monotherapies, but also safe (in contrast to LABA monotherapies) [21]. In the last years, long-acting muscarinic antagonists (LAMA), such as tiotropium, were approved as add-on bronchodilators for asthma treatment, either in separate inhalers or as a single inhaler triple therapy (ICS/LABA/LAMA) [22].

- In 1997, as another anti-inflammatory "controller," the oral leukotriene receptor antagonist (LTRA) montelukast was approved for asthma treatment [23]. Although it became widely used in clinical practice, mainly in younger patients with asthma, it turned out to be less effective than ICS in the majority of patients with asthma. In addition, it did not show effectiveness in patients with severe asthma.

- Since 2005, biologics were approved for the treatment of severe asthma. The first biologic, the anti-IgE antibody omalizumab, was followed by the anti-interleukin (IL)-5 (R) antibodies mepolizumab, reslizumab, and benralizumab, and the anti-IL-4 receptor-alpha antibody dupilumab [24]. These antibodies are currently recommended as the treatment of choice for patients with severe asthma [25]. In addition, these compounds can have beneficial effects on typical asthma comorbidities such as chronic spontaneous urticaria 
Fig. 2. Immunopathology and immune modulation of "type 2 high" asthma. There are 2 main pathways in the pathogenesis of airway inflammation in "type 2 high" asthma: via allergen-presenting dendritic cells (DC) which expand allergen-specific Thelper cells (Th2) and/or via an activation of ILC2. Both cell types are regulated by the transcription factor GATA-3. Both pathways can be triggered by epithelial cytokines (such as TSLP, IL-25, IL-33) and result in a release of type 2 cytokines such as IL-4, IL-5, or IL-13, and an enhanced IgE production by B cells. Immune-modulatory interventions that have been studied in clinical trials are shown (currently approved interventions for the treatment of asthma are marked with green color).

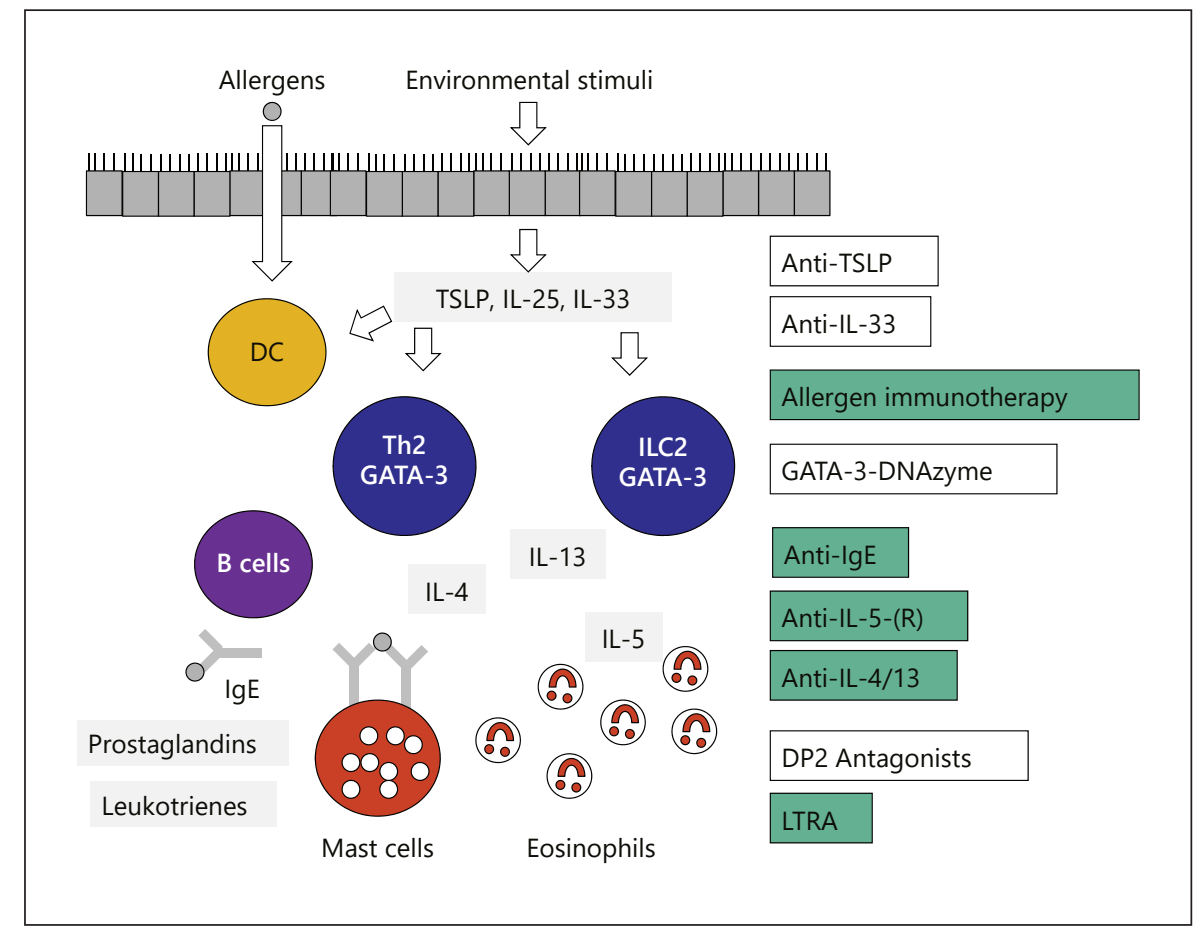

(CsU) [26], CRSwNP [27], or atopic dermatitis (AD) [28]. For the latter effects on comorbidities, the term "collateral efficacy" was introduced by Prof. Eric Bateman (Cape Town, South Africa).

Asthma treatment strategies in the 20th century (such as systemic steroids and ICS, short-acting and long-acting bronchodilators, or LTRAs) were intended as a uniform therapeutic scheme for all patients with the diagnosis "asthma." Since the advent of highly effective biologics in the 21 st century for specific asthma phenotypes, this concept has fundamentally changed towards an individually tailored therapy of chronic airway diseases based on treatable traits ("precision medicine") [2, 24, 29]. Therefore, in order to develop new and even more effective immune-modulatory strategies for specific traits [30], it is essential to better understand the complex immunopathology of asthma.

\section{Immunopathology of Asthma}

Asthma is a chronic inflammatory airway disease associated with a typical pattern of cytokine production, a typical distribution of inflammatory cells (such as eosinophils), an overproduction of mucus, and a dysfunction of structural cells in the airways, including epithelial cells, smooth muscle cells, and nerves [31]. There is growing evidence suggesting that the origin of asthma is linked to altered properties of the airway epithelium [32]. An abnormal secretion of mediators (such as IL-33, IL-25, or TSLP) by epithelial cells in response to exposure with bacteria, fungi, viruses, allergens, or pollutants can alter the subepithelial matrix and the function of neurons, vessels, and smooth muscle cells in the airway, and attract and activate specific immune cells $[33,34]$. Several types of immune cells, such as dendritic cells, T cells (including Th1 cells, Th2 cells, Th9 cells, Th17 cells, and Th22 cells), $\mathrm{B}$ cells, and innate lymphoid cells, play a role in the pathogenesis of airway inflammation in asthma $[34,35]$. However, two main pathogenetic pathways are currently being discussed (Fig. 2). The first is driven by the adaptive immune system: dendritic cells take up allergens from the environment and stimulate allergen-specific type $2 \mathrm{~T}$ helper cells (Th2 cells, expressing the transcription factor GATA3) which orchestrate and perpetuate an allergic inflammation in the airways, and secrete type 2 cytokines such as IL-4, IL-5, or IL-13 [34]. The second pathway is driven by the innate immune system: type 2 innate lymphoid cells (ILC2; which also express the transcription factor GATA3) are activated in response to epithelial cytokines (primarily IL-25, IL-33, TSLP) and do not only produce type 2 cytokines (IL-4, IL-5, IL-13), but also large 
amounts of IL-9 that can promote goblet cell metaplasia and promote mast cell growth and survival. Via a secretion of IL-4, Th2 cells stimulate allergen-specific IgE synthesis, whereas ILC2 can promote polyclonal IgE synthesis [34].

Due to the secretion of type 2 cytokines by both Th2 cells and ILC2, and the similarities of the resulting inflammation (including airway eosinophilia) and airway dysfunction, the umbrella term "type 2 asthma" (or "type 2 high asthma") was coined for both pathways [30]. The Th2 pathway is currently thought to be rather associated with early-onset, allergic asthma, and the ILC2 pathway rather with adult-onset, non-allergic asthma [30]. However, both pathways can be activated simultaneously in patients with asthma: it appears that each patient is characterized by an individual mixture and intensity of these pathways [34] (Fig. 2). Currently, increased numbers of eosinophils in sputum or peripheral blood, increased amounts of exhaled NO (fraction of exhaled NO, FeNO, measured in parts per billion, $\mathrm{ppb}$ - this molecule is released by airway epithelial cells following IL-13 stimulation) or the presence of typical allergies are considered as biomarkers of "type 2 high asthma" [30]. Some patients with the diagnosis of asthma, however, do not display any type 2 biomarker, and are classified as "type 2 low asthma" [36]. The latter form of asthma is currently poorly understood, and treatment options are very limited. In the following section, current and potential future options of immune modulation in asthma are discussed.

\section{Current and Potential Future Options of Immune Modulation in Asthma}

\section{Inhaled Corticosteroids}

ICS are currently the mainstay of asthma treatment, both for patients with mild disease and for patients with more severe asthma forms [19]. These compounds do not only act as immunosuppressants, but can have a beneficial effect on structural cells in the airways, such as epithelial cells, nerves, and smooth muscles [37]. In addition, recent evidence suggests that optimized ICS treatment in pregnant women with asthma can substantially decrease the risk of asthma in newborns [38]. A wide range of ICS doses are currently used in clinical practice. There is an enhanced risk of local and systemic adverse effects with increasing ICS doses [39]. It has been postulated that high doses of ICS are comparable with a daily oral dose of up to $5 \mathrm{mg}$ prednisolone per day [40]. This is probably the explanation for the strong reduction of eosinophil con-

Immune Modulation in Asthma: Current

Concepts and Future Strategies centrations in peripheral blood (by nearly $50 \%$ ) following an increase of the daily ICS treatment from a medium to a high dose [41]. Therefore, it is currently debated whether high doses of ICS are an acceptable long-term treatment option for asthma or whether other immune-modulating treatment strategies with less adverse effects should be preferred. It has been generally accepted that, due to the synergistic effects of ICS and LABA [42], fixed combinations of these compounds with lower ICS doses should be preferred over high-dose ICS monotherapies in patients with asthma.

\section{Allergen Immunotherapy}

AIT (formerly called specific immunotherapy) is the oldest form of immune modulation in allergic airway diseases and was initially described by Leonard Noon in 1911 [7]. Over the last 100 years, some of the complex mechanisms of AIT have been elucidated. The regular application of high doses of the allergens in conjunction with various types of adjuvants restores dendritic cell function, promotes immune deviation from Th2 to Th1 responses, induces $\mathrm{T}$ regulatory cells (Tregs), and promotes $\mathrm{B}$ regulatory cells (Bregs) that produce blocking antibodies (such as IgA or IgG4) [43]. These mechanisms lead to a persistent reduction of allergic airway responses, even after treatment withdrawal [43]. Several routes of AIT are currently explored, including subcutaneous (SCIT), sublingual (SLIT), intralymphatic, epicutaneous, or oral AIT [8]. Most of the evidence regarding AIT efficacy in allergic asthma was derived from studies testing SCIT effects on allergic rhinitis (which contained subpopulations of patients with allergic asthma) [44]. Due to safety concerns and lacking studies with patients with not well-controlled asthma, recommendations for AIT in allergic asthma were limited to patients with well-controlled asthma and preserved lung function $\left(\mathrm{FEV}_{1}>80 \%\right)$. Although SLIT is associated with a lower risk of anaphylactic reactions than SCIT, the lack of large-scale studies testing SLIT effects in asthma hampered the use of this AIT form in clinical practice. This changed after publication of the MITRA study which demonstrated that SLIT can be safe and effective in patients with house dust mite allergy and not wellcontrolled asthma (and a $\mathrm{FEV}_{1}$ down to $70 \%$ of the predicted value) [45]. These results led to the current recommendation by GINA that SLIT can be considered in patients who have partly controlled allergic asthma despite ICS therapy, a proven house dust mite allergy, and a $\mathrm{FEV}_{1}>70 \%$ predicted (www.ginasthma.com). Further studies using SCIT and SLIT (and possibly other routes 
of AIT) are awaited to better understand the efficacy and safety of AIT in patients with not well-controlled allergic asthma.

\section{Aspirin Desensitization}

Aspirin-exacerbated respiratory disease (AERD; also known as aspirin intolerance) is characterized by the occurrence of asthma, nasal polyps (CRSwNP), and a sensitivity to COX-1 inhibitors such as aspirin ("Samter's triad" or "Widal triad") [46]. The prevalence of AERD ranges between $7 \%$ in the general population and 15\% among patients with severe asthma [46]. An effective treatment option for this patient population is aspirin desensitization which is achieved by starting at low doses of aspirin (administered either orally, nasally, or via inhalation) and gradually increasing the dose over a period of up to 3 days (during which drug-induced reactions become milder and then disappear). When the target dose (usually 300$500 \mathrm{mg}$ aspirin orally per day) is achieved, an additional ingestion of COX-1 inhibitors does not induce hypersensitivity reactions anymore. Long-term treatment can improve asthma control and markedly reduce the need for surgical interventions in the upper airways. It is interesting to note that neither the pathophysiology of this acquired disorder (AERD is never present at birth) nor the precise immunological effects of aspirin desensitization are fully understood [46]. In addition, it is unknown whether viruses or toxins are the inciting event of this disorder. Although AERD is characterized by high eosinophil counts and increased numbers of activated mast cells, there is no evidence that the pathophysiology of AERD is Th2 related. Several lines of evidence point to a complex interaction of epithelial cytokines, ILC2, leukotrienes, and prostaglandins in the pathogenesis of this disease [46]. In addition to local treatments of upper and lower airways, either medically (with nasal or inhaled steroids) or surgically (debulking of nasal polyps and functional endoscopic sinus surgery), aspirin desensitization was the only treatment option to avoid long-term OCS treatment. There is, however, recent evidence that biologics such as dupilumab can be a very effective AERD treatment [27]. Given the potential complications of longterm aspirin desensitization treatment in clinical practice (e.g., gastric pain, gastric ulcers, bleedings), biologics could be an alternative treatment option for AERD patients who do not tolerate aspirin desensitization.

\section{Leukotriene and Prostaglandin Receptor Antagonists}

Leukotrienes and prostaglandins are lipid mediators, belonging to the family of eicosanoids, which play a key role in chronic inflammatory airway diseases [47]. Cysleukotrienes (leukotriene C4, D4, and E4) are produced by various cells of the adaptive and innate immune system and induce chemotaxis of inflammatory cells, bronchoconstriction, mucus hypersecretion, airway wall ede$\mathrm{ma}$, and remodeling. Prostaglandins (prostaglandin E2, D2, F2a, and prostacyclin) are produced by prostanoid synthases which are mainly expressed by innate immune cells [47]. There is a large body of evidence showing that prostaglandin D2 can mediate eosinophil infiltration, bronchoconstriction, and cough in patients with asthma, predominantly via the prostaglandin $\mathrm{D}$ receptor 2 (DP2; formerly known as chemoattractant receptor-homologous molecule expressed on Th2 lymphocytes, CRTH2) [48]. The LTRA montelukast was approved for the treatment of asthma in 1997 and is still widely used in clinical practice. However, montelukast is less effective than ICS monotherapy in asthma. Furthermore, the addition of a LABA is more effective than the addition of montelukast in patients who are not well controlled with an ICS monotherapy [49]. Finally, montelukast is neither approved for nor (in most cases) effective in patients with severe asthma. Thus, montelukast is currently primarily used as an alternative treatment option in patients with mild or moderate asthma who are unwilling or unable to use ICS or ICS/LABA treatment. Prostaglandin D2 and its receptor (DP2) are upregulated in patients with severe asthma (as compared with patients with mild-to-moderate asthma) [50], and the number of submucosal DP2positive cells in the airways correlates with asthma severity [51]. Therefore, the development of DP2 antagonists was eagerly awaited as a new oral treatment option, especially for patients with more severe asthma. Indeed, phase 2 trials suggested that treatment with the DP2 antagonist fevipiprant (QAW039) is well tolerated, and associated with a reduction in sputum eosinophils [52] and an improvement in lung function in those patients with greater severity of airflow limitation $\left(\mathrm{FEV}_{1}<70 \%\right.$ predicted) [53]. However, the large phase 3 trials with fevipiprant (LUSTER 1 and 2: comparing doses of $150 \mathrm{mg}$ or $450 \mathrm{mg}$ fevipiprant once daily with placebo) did not reach the primary endpoint (reduction in the rate of moderate-to-severe exacerbations compared to placebo over a 52-week treatment period) and the development of fevipiprant for asthma was stopped in 2019 (press release on www.novartis.com on December 16, 2019). Phase 3 trials with timapiprant, another oral DP2 antagonist [54], are ongoing. It is currently unclear whether oral DP2 antagonists will become available in clinical practice. 


\section{Anti-IgE Antibodies}

Allergen-specific immunoglobulin E (IgE) is a key driver of allergen-induced exacerbations in patients with allergic asthma [55]. The removal of IgE can reduce allergen-induced IgE cross-linking on mast cells and, consequently, improve asthma control [55]. Clinical trials [56] and results from real-world studies [57] have demonstrated that treatment with the anti-IgE antibody omalizumab can substantially decrease exacerbation rates and the use of OCS in patients with severe allergic asthma. This led to the approval of omalizumab for this patient population in Europe in 2005. However, anti-IgE treatment with omalizumab was also effective in patients without evidence of allergies [58], suggesting that other mechanisms may contribute to the clinical effects of omalizumab [59]. Indeed, another anti-IgE antibody, ligelizumab, with stronger anti-allergic properties than omalizumab, was not effective in clinical trials with patients with allergic asthma; the clinical development of this antibody for asthma was stopped [60]. Surprisingly, anti-IgE treatment with omalizumab was shown to enhance antiviral immunity via a downregulation of the high-affinity IgE receptor on plasmacytoid dendritic cells (pDCs) which are essential for antiviral immune responses [61]. The PROSE (Preventative Omalizumab or StepUp Therapy for Severe Fall Exacerbations) study confirmed that the reduction of viral exacerbations in children with asthma following omalizumab treatment is mediated by a downregulation of the high-affinity IgE receptor on pDCs $[62,63]$. In addition, omalizumab was shown to be effective in the treatment of $\mathrm{CsU}$, an autoimmune disease of the skin [26] (the anti-IgE antibody ligelizumab is even more effective in patients with CsU [64]). In this disease, IgE antibodies are cross-linked by autoallergens in the skin (autoimmune type I) or by IgG autoantibodies against IgE (autoimmune type 2), resulting in recurrent mast cell degranulation [65]. Of note, autoimmune mechanisms are postulated to contribute to the pathogenesis of severe asthma [66]. Therefore, clinical effects of omalizumab treatment in patients with severe asthma are probably explained by several mechanisms: antiallergic effects, antiviral effects, and antiautoimmune effects. In addition, the concept that the dose of omalizumab needs to be adapted to the individual IgE serum concentration has been challenged by the observation that a fixed dose of omalizumab is effective in patients with CsU [26] or allergic bronchopulmonary aspergillosis [67] who have a large variety of IgE serum concentrations. Thus, the example of omalizumab shows that biologics have immune-modulatory effects which are far more complex than the suggested "straight stories" published at the time of approval of the antibodies.

\section{Anti-IL-5 and Anti-IL-5 Receptor Antibodies}

Eosinophilia in the airways and in peripheral blood was already described as a central feature of asthma more than 100 years ago by Francis M. Rackemann [6]. He also noted that patients with intrinsic (non-allergic) asthma display higher eosinophil numbers than patients with extrinsic (allergic) asthma [6]. The latter observation led to the term "eosinophilic asthma" which is currently mainly used for intrinsic asthma. As noted above, eosinophilia can be the result both of the Th2 pathway and the ILC2 pathway of airway inflammation in asthma, making it a general type 2 biomarker which occurs "downstream" in inflammatory pathways in asthma [31]. Eosinophils play a central pathogenetic role in asthma [56]. IL-5 is essential for the development, recruitment, and survival of eosinophils; therefore, it is not surprising that antibodies targeting IL-5 or its receptor were developed for the treatment of asthma [68]. Since 2015, two antibodies targeting IL-5 (mepolizumab and reslizumab) and one antibody targeting the IL-5 receptor (benralizumab) were approved for the treatment of severe, eosinophilic asthma. Treatment with mepolizumab or reslizumab leads to a reduction in peripheral blood eosinophils (to "normal" ranges between 50 and 150 cells $/ \mu \mathrm{L}$ ), whereas treatment with benralizumab leads to a complete depletion of eosinophils in peripheral blood $(0$ cells/ $\mu \mathrm{L}$ for several weeks after application) [24].

Clinical trials demonstrated that treatment with these antibodies results in strong reductions in exacerbation rates and improvements in asthma control and even lung function in patients with severe asthma [69-71]. In addition, these antibodies lead to a substantial decrease in the need for long-term OCS therapy [72, 73]. Blood eosinophils are currently the best predictor for a clinical effectiveness of anti-IL-5-(R) antibodies in severe asthma the higher the blood eosinophil count, the higher the likelihood of a treatment response [74]. As in the case of anti-IgE treatment, there are currently no significant adverse effects or safety signals reported during anti-IL5 -(R) treatment over a period several years $[75,76]$. In clinical practice, the vast majority of the patients treated with these biologics do not report any adverse effects. Even in patients with complete depletion of blood eosinophils (benralizumab treatment) no safety signals have been reported so far [76]. This led to the hypothesis that eosinophils may not be necessary for normal functioning of the human immune system ("appendix of the immune 
system") [77]. However, long-term safety data for antiIL-5-(R) antibody treatment over a period of more than 10 years are currently not available. In addition, there are currently no head-to-head studies comparing the clinical effectiveness of the 3 anti-IL-5-(R) antibodies. There is accumulating evidence suggesting that anti-IL-5-(R) antibodies are most effective in patients with adult-onset asthma [78]. Of note, treatment with anti-IL-5-(R) antibodies such as mepolizumab and benralizumab can also be effective in patients with evidence of hypereosinophilia and/or vasculitis $[79,80]$, and in patients with CRSwNP [81].

\section{Anti-IL-4 Receptor-Alpha Antibody}

The cytokines IL- 4 and IL-13 are key mediators of airway inflammation in asthma [34]. However, clinical trials using blocking antibodies either against IL-4 [82] or IL$13[83,84]$ showed limited and inconsistent efficacy in patients with severe asthma. In contrast, phase 2 trials with the anti-IL-4 receptor alpha antibody dupilumab which blocks both IL-4 and IL-13 (the alpha unit of the IL-4 receptor is also part of the IL-13 receptor) demonstrated substantial beneficial effects on exacerbation rates, asthma control, and lung function in patients with severe asthma [85]. This was confirmed by phase 3 trials [86]. In addition, it was shown that dupilumab treatment decreases the need for long-term OCS therapy [87]. These data led to the approval of dupilumab for the treatment of severe asthma in 2019. Dupilumab can be effective both in patients with early-onset, allergic asthma (the typical target population of the anti-IgE antibody omalizu$\mathrm{mab}$ ) and in patients with adult-onset, non-allergic asthma (the typical target population of anti-IL-5-(R) antibodies). Given this broad potential target population, biomarkers appear to be even more important in the case of dupilumab to predict the clinical responses. In contrast to the anti-IL-5-(R) antibodies (with one main predictor of a clinical response: eosinophils), there are currently two predictors of a dupilumab treatment response: either a blood eosinophil count $>150$ cells/ $\mu \mathrm{L}$ blood or an FeNO value $>25 \mathrm{ppb}$ [86]. The latter biomarker (FeNO) was part of the approval by the European Medical Agency (EMA); thus, dupilumab is the first compound in asthma history which is approved in conjunction with a FeNO measurement.

Of note, dupilumab was not only approved for the treatment of severe asthma, but also for the treatment of $\mathrm{AD}[28,88]$ and CRSwNP [27]. In the study which led to the approval of dupilumab for CRSwNP [27], dupilumab was also very effective in the subpopulation of patients with aspirin-exacerbated disease (AERD) [46]. Thus, as already mentioned for other biologics, these compounds do not only have minimal or even absent side effects (low "collateral damage"), but can also have substantial beneficial effects on typical comorbidities (high "collateral efficacy"). It is still puzzling that biologics can have similar clinical effects on asthma, although the effects on measured biomarkers are very different (Fig. 3). For instance, blood eosinophil counts are strongly reduced during anti-IL-5-(R) antibody treatment, but increase temporarily during dupilumab treatment (Fig. 3). The latter effect has been explained by an inhibition of the expression of VCAM- 1 and ICAM- 1 which is dependent on IL-4 receptor alpha and essential for eosinophil extravasation [34].

\section{Antibodies Targeting Epithelial Cytokines (TSLP,}

IL-33, IL-25)

The biologics described above inhibit mediators (IL4, IL-13, IL-5) or antibodies (IgE) which are "downstream" in the inflammatory pathways of asthma. Some patients treated with these biologics do not respond to these therapies ("non-responders") or exhibit only a partial response ("partial responder") [89]. Therefore, new and possibly more effective immune-modulatory strategies for asthma are currently explored. One concept is to block epithelial cytokines which are "upstream" of the inflammatory pathways, namely TSLP, IL-33, or IL-25. These mediators are released from epithelial cells in response to a broad array of stimuli, including allergens, mechanical injury, infective agents, or proteases, and promote type 2 cytokine responses [90, 91]. Blocking these mediators bears the risk of infections, because these epithelial mediators are not only important for inflammatory processes in asthma, but also for the prevention of infections [92]. TSLP, a member of the IL-2 cytokine family, can activate both Th2 cells and ILC2, whereas IL33 , a member of the IL-1 cytokine family, is a particularly potent activator of ILC2 [90]. The role of IL-25, a member of the IL-17 cytokine family, in asthma is currently less clear. Human data on the role of IL-25 in asthma are limited and antibodies targeting IL-25 are in a very early stage of development [90]. In contrast, there is accumulating evidence from clinical studies that treatment with antibodies against TLSP and IL-33 might be beneficial and safe in patients with asthma. A phase 2 trial exploring 3 different doses of the anti-TSLP antibody tezepelumab in patients with severe asthma demonstrated a strong decrease in exacerbation rates, even in those patients treated with the lowest dose [93]. Notably, 


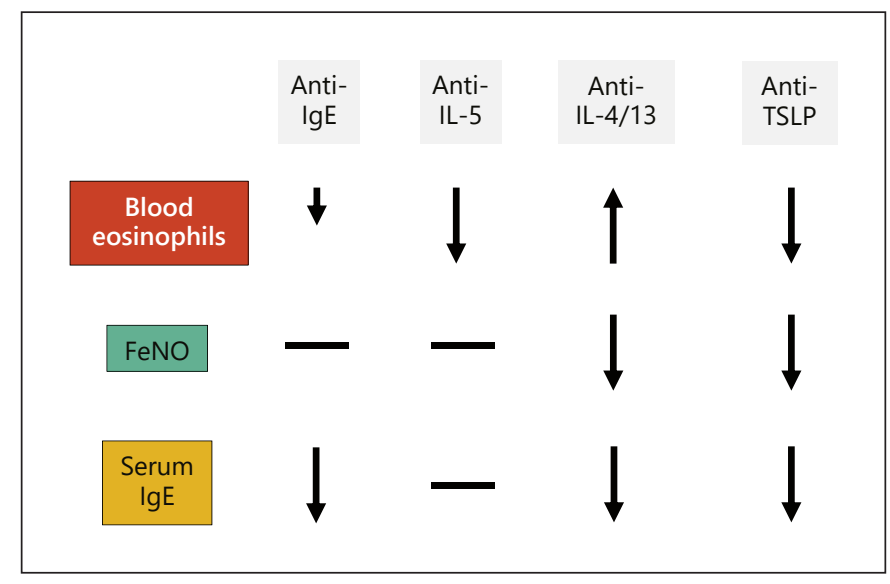

Fig. 3. Changes of asthma biomarkers during a treatment with biologics: blood eosinophil counts, FeNO values, and total IgE serum concentrations during treatment with anti-IgE (omalizumab), anti-IL-5-(R) (mepolizumab, reslizumab, benralizumab), antiIL-4/13 (dupilumab), or anti-TSLP (tezepelumab) in published clinical trials with patients with severe asthma.

the effect of tezepelumab was independent from baseline type 2 markers such as eosinophils or FeNO [93]. In addition, tezepelumab is the first biologic that reduces all three asthma biomarkers: eosinophils, FeNO, and total IgE in serum (Fig. 3). Finally, there were no safety signals in this trial, especially no increase in infections in tezepelumab-treated patients [93]. A small phase 2a trial (NCT03469934) demonstrated that a single dose (300 mg intravenously) of the anti-IL-33 antibody etokimab can result in an improvement in lung function and asthma control in adult patients with severe eosinophilic asthma [94]. Of note, beneficial effects of etokimab were also shown in phase 2 trials in patients with atopic dermatitis [95] and in patients with peanut allergy [96]. In addition, an antibody blocking the IL-33 receptor ST2 (MSTT1041A) is currently being tested in a phase 2a asthma trial [24]. However, phase 3 trials with tezepelumab or etokimab (or antibodies targeting the receptors of TSLP or IL-33) have not yet been published, and these compounds are not yet approved for the treatment of asthma or other conditions.

\section{Other Potential Future Options for Immune \\ Modulation in Asthma}

It has been shown as feasible to reduce allergen-induced airway inflammation via inhalation of a DNA enzyme that targets the type 2 master transcription factor GATA3 (which is expressed both by Th2 cells and by ILC2) [97]; phase 3 trials with this compound are cur- rently lacking. Impaired interferon (IFN) responses contribute to the pathogenesis of viral exacerbations in asthma [98]. Therefore, inhalation of IFN-beta has been discussed as a potential treatment of asthma exacerbations. However, clinical trials exploring the effects of inhaled IFN-beta on asthma exacerbations did not show consistent benefits $[99,100]$. In contrast, there are encouraging early-phase clinical studies with nebulized ensifentrine, an inhaled dual phosphodiesterase (PDE) $3 / 4$ inhibitor, in patients with asthma [101]; this compound will also be tested in patients with COPD [102]. It is well established that farm-like indoor microbiota protect children from asthma development [103]. Therefore, interventions targeting the microbiome during infancy are currently explored to prevent and to treat asthma [104, 105]; clinical applications of this concept are not yet available.

\section{Potential Options for "Type 2 Low Asthma"}

A minority of patients with severe asthma do not display any type 2 marker and do not respond to biologics that target type 2 pathways ("type 2 low asthma"). Therefore, it is important to explore new treatment options for this patient population. One potential future option for these patients is a treatment with antibodies targeting epithelial cytokines such as tezepelumab [93], as mentioned above. There are, however, a number of additional potential immunologic targets in patients with type 2 low asthma [36]. For instance, anti-IL-6 antibodies, which have already been approved for the treatment of rheumatoid arthritis, could become a treatment option for a type 2 low asthma subpopulation with an IL-6-dominated phenotype [106]. Anti-IL-17 antibodies, which have already been approved for the treatment of psoriasis, might be helpful in patients with enhanced IL-17 expression and features of a psoriasis immunophenotype [107]. Results of a phase 2 trial with the anti-IL17 antibody CJM112 in patients with inadequately controlled moderate-tosevere asthma will be published in the near future (NCT03299686).

\section{Conclusions}

Asthma treatment concepts have profoundly changed over the last 20 years, from standard therapeutic regimens for all patients with asthma towards individually tailored interventions targeting specific asthma endotypes or phenotypes. A precise and highly effective immune modulation with minimal adverse effects plays a central role in 
this new concept. Indeed, there have been major advances in the treatment of asthma with immune-modulatory compounds (such as biologics for severe asthma) in the last 2 decades. New immune-modulatory strategies are expected to enter clinical practice in the future, especially for those patients with treatment-resistant asthma.

\section{Disclosure Statement}

The author received research grants from Deutsche Forschungsgemeinschaft (DFG), GSK, Astra Zeneca, and honoraria for lectures and advisory boards from ALK, Allergopharma, Astra Zeneca, Bencard, Berlin-Chemie, Boehringer-Ingelheim, Bosch, Chiesi, Circassia, GSK, HAL Allergy, Janssen-Cilag, MSD, Mundipharma, Novartis, Nycomed/Takeda, Sanofi, TEVA, UCB.

\section{References}

1 Lemanske RF Jr, Busse WW. Asthma: clinical expression and molecular mechanisms. J Allergy Clin Immunol. 2010 Feb;125(2 Suppl 2):S95-102.

2 Pavord ID, Beasley R, Agusti A, Anderson GP, Bel E, Brusselle G, et al. After asthma: redefining airways diseases. Lancet. 2018 Jan; 391(10118):350-400.

3 To T, Stanojevic S, Moores G, Gershon AS, Bateman ED, Cruz AA, et al. Global asthma prevalence in adults: findings from the crosssectional world health survey. BMC Public Health. 2012 Mar;12(1):204.

4 Soriano JB, Abajobir AA, Abate $\mathrm{KH}$, Abera SF, Agrawal A, Ahmed MB, et al.; GBD 2015 Chronic Respiratory Disease Collaborators. Global, regional, and national deaths, prevalence, disability-adjusted life years, and years lived with disability for chronic obstructive pulmonary disease and asthma, 1990-2015: a systematic analysis for the Global Burden of Disease Study 2015. Lancet Respir Med. 2017 Sep;5(9):691-706.

5 von Mutius E, Drazen JM. A patient with asthma seeks medical advice in 1828, 1928, and 2012. N Engl J Med. 2012 Mar;366(9): 827-34.

6 Rackemann FM. A clinical study of one hundred and fifty cases of bronchial asthma. Arch Intern Med. 1918;12(4):517-52.

7 Durham SR, Nelson H. Allergen immunotherapy: a centenary celebration. World Allergy Organ J. 2011 Jun;4(6):104-6.

8 Pfaar O, Agache I, de Blay F, Bonini S, Chaker AM, Durham SR, et al. Perspectives in allergen immunotherapy: 2019 and beyond. $\mathrm{Al}-$ lergy. 2019 Dec;74(S108 Suppl 108):3-25.

9 Brown HM. Treatment of chronic asthma with prednisolone; significance of eosinophils in the sputum. Lancet. 1958 Dec;2(7059): $1245-7$.

10 Bloechliger M, Reinau D, Spoendlin J, Chang SC, Kuhlbusch K, Heaney LG, et al. Adverse events profile of oral corticosteroids among asthma patients in the UK: cohort study with a nested case-control analysis. Respir Res. 2018 Apr;19(1):75.

11 Sweeney J, Patterson CC, Menzies-Gow A, Niven RM, Mansur AH, Bucknall C, et al.; British Thoracic Society Difficult Asthma Network. Comorbidity in severe asthma requiring systemic corticosteroid therapy: cross-sectional data from the Optimum Patient Care Research Database and the British
Thoracic Difficult Asthma Registry. Thorax. 2016 Apr;71(4):339-46.

12 Price DB, Trudo F, Voorham J, Xu X, Kerkhof M, Ling Zhi Jie J, et al. Adverse outcomes from initiation of systemic corticosteroids for asthma: long-term observational study. J Asthma Allergy. 2018 Aug;11:193-204.

13 Choo-Kang YF, Simpson WT, Grant IW. Controlled comparison of the bronchodilator effects of three beta-adrenergic stimulant drugs administered by inhalation to patients with asthma. BMJ. 1969 May;2(5652):287-9.

14 Inman WH, Adelstein AM. Rise and fall of asthma mortality in England and Wales in relation to use of pressurised aerosols. Lancet. 1969 Aug;2(7615):279-85.

15 Lommatzsch M, Lindner Y, Edner A, Bratke K, Kuepper M, Virchow JC. Adverse effects of salmeterol in asthma: a neuronal perspective. Thorax. 2009 Sep;64(9):763-9.

16 Johnston SL, Edwards MR. Mechanisms of adverse effects of $\{$ beta\}-agonists in asthma. Thorax. 2009 Sep;64(9):739-41.

17 Brown HM, Storey G, George WH. Beclomethasone dipropionate: a new steroid aerosol for the treatment of allergic asthma. BMJ. 1972 Mar; 1(5800):585-90.

18 Crompton G. A brief history of inhaled asthma therapy over the last fifty years. Prim Care Respir J. 2006 Dec;15(6):326-31.

19 Papi A, Brightling C, Pedersen SE, Reddel HK. Asthma. Lancet. 2018 Feb;391(10122): 783-800.

20 Reddel HK, Busse WW, Pedersen S, Tan WC, Chen YZ, Jorup C, et al. Should recommendations about starting inhaled corticosteroid treatment for mild asthma be based on symptom frequency: a post-hoc efficacy analysis of the START study. Lancet. 2017 Jan; 389(10065):157-66.

21 Busse WW, Bateman ED, Caplan AL, Kelly HW, O'Byrne PM, Rabe KF, et al. Combined Analysis of Asthma Safety Trials of Long-Acting $\beta 2$-Agonists. N Engl J Med. 2018 Jun; 378(26):2497-505.

22 Virchow JC, Kuna P, Paggiaro P, Papi A, Singh D, Corre S, et al. Single inhaler extrafine triple therapy in uncontrolled asthma (TRIMARAN and TRIGGER): two double-blind, parallel-group, randomised, controlled phase 3 trials. Lancet. 2019 Nov;394(10210):173749.

23 Currie GP, McLaughlin K. The expanding role of leukotriene receptor antagonists in chronic asthma. Ann Allergy Asthma Immunol. 2006;97:731-42. https://doi.org/10.1016/ S1081-1206(10)60963-5.

24 Corren J. New Targeted Therapies for Uncontrolled Asthma. J Allergy Clin Immunol Pract. 2019 May - Jun;7(5):1394-403.

25 Lommatzsch M. [Treatment of refractory asthma with antibodies]. Dtsch Med Wochenschr. 2016 Jun;141(11):790-3.

26 Maurer M, Rosén K, Hsieh HJ, Saini S, Grat$\tan \mathrm{C}$, Gimenéz-Arnau A, et al. Omalizumab for the treatment of chronic idiopathic or spontaneous urticaria. N Engl J Med. 2013 Mar;368(10):924-35.

27 Bachert C, Han JK, Desrosiers M, Hellings PW, Amin N, Lee SE, et al. Efficacy and safety of dupilumab in patients with severe chronic rhinosinusitis with nasal polyps (LIBERTY NP SINUS-24 and LIBERTY NP SINUS-52): results from two multicentre, randomised, double-blind, placebo-controlled, parallelgroup phase 3 trials. Lancet. 2019 Nov; 394(10209):1638-50.

28 Blauvelt A, de Bruin-Weller M, Gooderham M, Cather JC, Weisman J, Pariser D, et al. Long-term management of moderate-to-severe atopic dermatitis with dupilumab and concomitant topical corticosteroids (LIBERTY AD CHRONOS): a 1-year, randomised, double-blinded, placebo-controlled, phase 3 trial. Lancet. 2017 Jun;389(10086):2287303.

29 Lommatzsch M, Stoll P. Novel strategies for the treatment of asthma. Allergo J Int. 2016; 25(1):11-7.

30 Chung KF, Adcock IM. Precision medicine for the discovery of treatable mechanisms in severe asthma. Allergy. 2019 Sep;74(9):164959.

31 Lambrecht BN, Hammad H. The immunology of asthma. Nat Immunol. 2015 Jan;16(1): 45-56.

32 Holgate ST. The sentinel role of the airway epithelium in asthma pathogenesis. Immunol Rev. 2011 Jul;242(1):205-19.

33 Al-Muhsen S, Johnson JR, Hamid Q. Remodeling in asthma. J Allergy Clin Immunol. 2011 Sep;128(3):451-62.

34 Lambrecht BN, Hammad H, Fahy JV. The Cytokines of Asthma. Immunity. 2019 Apr; 50(4):975-91.

35 Robinson DS. The role of the $\mathrm{T}$ cell in asthma. J Allergy Clin Immunol. 2010 Dec;126(6): 1081-93. 
36 Kalchiem-Dekel O, Yao X, Levine SJ. Meeting the Challenge of identifying new treatments for type 2-low neutrophilic asthma. Chest. 2020 Jan;157(1):26-33.

37 Lommatzsch M. Airway hyperresponsiveness: new insights into the pathogenesis. Semin Respir Crit Care Med. 2012 Dec;33(6) 579-87.

38 Morten M, Collison A, Murphy VE, Barker D, Oldmeadow C, Attia J, et al. Managing Asthma in Pregnancy (MAP) trial: FENO levels and childhood asthma. J Allergy Clin Immunol. 2018 Dec;142(6):1765-1772.e4.

39 Beasley R, Harper J, Bird G, Maijers I, Weatherall M, Pavord ID. Inhaled Corticosteroid Therapy in Adult Asthma. Time for a New Therapeutic Dose Terminology. Am J Respir Crit Care Med. 2019 Jun;199(12):1471-7.

40 Maijers I, Kearns N, Harper J, Weatherall M, Beasley R. Oral steroid sparing effect of high dose inhaled corticosteroids in asthma. Eur Respir J. 2020;55(1):1901147.

41 Lommatzsch M, Klein M, Stoll P, Virchow JC. Impact of an increase in the inhaled corticosteroid dose on blood eosinophils in asthma. Thorax. 2019 Apr;74(4):417-8.

42 Miller SM, Ortega VE. Pharmacogenetics and the development of personalized approaches for combination therapy in asthma. Curr Allergy Asthma Rep. 2013 Oct;13(5):443-52.

43 Shamji MH, Durham SR. Mechanisms of allergen immunotherapy for inhaled allergens and predictive biomarkers. J Allergy Clin Immunol. 2017 Dec;140(6):1485-98.

44 Abramson MJ, Puy RM, Weiner JM. Injection allergen immunotherapy for asthma. Cochrane Database Syst Rev. 2010 Aug;(8): CD001186.

45 Virchow JC, Backer V, Kuna P, Prieto L, Nolte $\mathrm{H}$, Villesen $\mathrm{HH}$, et al. Efficacy of a house dust mite sublingual allergen immunotherapy tablet in adults with allergic asthma: A randomized clinical trial. JAMA. 2016 Apr;315(16) 1715-25.

46 White AA, Stevenson DD. Aspirin-Exacerbated Respiratory Disease. N Engl J Med. 2018 Sep;379(11):1060-70.

47 Diamant Z, Aalders W, Parulekar A, Bjermer L, Hanania NA. Targeting lipid mediators in asthma: time for reappraisal. Curr Opin Pulm Med. 2019 Jan;25(1):121-7.

48 Domingo C, Palomares O, Sandham DA, Erpenbeck VJ, Altman P. The prostaglandin D2 receptor 2 pathway in asthma: a key player in airway inflammation. Respir Res. 2018 Sep; 19(1):189.

49 Chauhan BF, Ducharme FM. Addition to inhaled corticosteroids of long-acting beta2-agonists versus anti-leukotrienes for chronic asthma. Cochrane Database Syst Rev. 2014 Jan;1:CD003137.

50 Balzar S, Fajt ML, Comhair SA, Erzurum SC, Bleecker E, Busse WW, et al. Mast cell phenotype, location, and activation in severe asthma. Data from the Severe Asthma Research Program. Am J Respir Crit Care Med. 2011 Feb;183(3):299-309.
51 Stinson SE, Amrani Y, Brightling CE. D prostanoid receptor 2 (chemoattractant receptorhomologous molecule expressed on $\mathrm{TH} 2$ cells) protein expression in asthmatic patients and its effects on bronchial epithelial cells. J Allergy Clin Immunol. 2015 Feb;135(2):395406.

52 Gonem S, Berair R, Singapuri A, Hartley R, Laurencin MF, Bacher G, et al. Fevipiprant, a prostaglandin D2 receptor 2 antagonist, in patients with persistent eosinophilic asthma: a single-centre, randomised, double-blind, parallel-group, placebo-controlled trial. Lancet Respir Med. 2016 Sep;4(9):699-707.

53 Erpenbeck VJ, Popov TA, Miller D, Weinstein SF, Spector S, Magnusson B, et al. The oral CRTh2 antagonist QAW039 (fevipiprant): a phase II study in uncontrolled allergic asthma. Pulm Pharmacol Ther. 2016 Aug;39: 54-63.

54 Pettipher R, Hunter MG, Perkins CM, Collins LP, Lewis T, Baillet M, et al. Heightened response of eosinophilic asthmatic patients to the CRTH2 antagonist OC000459. Allergy. 2014 Sep;69(9):1223-32.

55 Holgate S, Casale T, Wenzel S, Bousquet J, Deniz Y, Reisner C. The anti-inflammatory effects of omalizumab confirm the central role of IgE in allergic inflammation. J Allergy Clin Immunol. 2005 Mar;115(3):459-65.

56 Israel E, Reddel HK. Severe and Difficult-toTreat Asthma in Adults. N Engl J Med. 2017 Sep;377(10):965-76

57 Brusselle G, Michils A, Louis R, Dupont L, Van de Maele B, Delobbe A, et al. "Real-life" effectiveness of omalizumab in patients with severe persistent allergic asthma: the PERSIST study. Respir Med. 2009 Nov;103(11): 1633-42.

58 Garcia G, Magnan A, Chiron R, ContinBordes C, Berger P, Taillé C, et al. A proof-ofconcept, randomized, controlled trial of omalizumab in patients with severe, difficultto-control, nonatopic asthma. Chest. 2013 Aug;144(2):411-9.

59 Lommatzsch M, Korn S, Buhl R, Virchow JC. Against all odds: anti-IgE for intrinsic asthma? Thorax. 2014 Jan;69(1):94-6.

60 Gasser P, Tarchevskaya SS, Guntern P, Brigger D, Ruppli R, Zbären N, et al. The mechanistic and functional profile of the therapeutic anti-IgE antibody ligelizumab differs from omalizumab. Nat Commun. 2020 Jan;11(1): 165.

61 Gill MA, Liu AH, Calatroni A, Krouse RZ, Shao B, Schiltz A, et al. Enhanced plasmacytoid dendritic cell antiviral responses after omalizumab. J Allergy Clin Immunol. 2018 May;141(5):1735-1743.e9.

62 Teach SJ, Gill MA, Togias A, Sorkness CA, Arbes SJ Jr, Calatroni A, et al. Preseasonal treatment with either omalizumab or an inhaled corticosteroid boost to prevent fall asthma exacerbations. J Allergy Clin Immunol. 2015 Dec;136(6):1476-85.

63 Esquivel A, Busse WW, Calatroni A, Togias AG, Grindle KG, Bochkov YA, et al. Effects of
Omalizumab on Rhinovirus Infections, Illnesses, and Exacerbations of Asthma. Am J Respir Crit Care Med. 2017 Oct;196(8):98592.

64 Maurer M, Giménez-Arnau AM, Sussman G Metz M, Baker DR, Bauer A, et al. Ligelizumab for chronic spontaneous urticaria. N Engl J Med. 2019 Oct;381(14):1321-32.

65 Maurer M, Pucillo C. What we know (and don't know) about the biology and functions of mast cells and basophils. Immunol Rev. 2018 Mar;282(1):5-7.

66 Mukherjee M, Nair P. Autoimmune Responses in Severe Asthma. Allergy Asthma Immunol Res. 2018 Sep;10(5):428-47.

67 Voskamp AL, Gillman A, Symons K, Sandrini A, Rolland JM, O'Hehir RE, et al. Clinical efficacy and immunologic effects of omalizumab in allergic bronchopulmonary aspergillosis. J Allergy Clin Immunol Pract. 2015 Mar-Apr;3(2):192-9.

68 Legrand F, Klion AD. Biologic therapies targeting eosinophils: current status and future prospects. J Allergy Clin Immunol Pract. 2015 Mar-Apr;3(2):167-74.

69 Ortega HG, Liu MC, Pavord ID, Brusselle GG, FitzGerald JM, Chetta A, et al.; MENSA Investigators. Mepolizumab treatment in patients with severe eosinophilic asthma. N Engl J Med. 2014 Sep;371(13):1198-207.

70 Corren J, Weinstein S, Janka L, Zangrilli J, Garin $\mathrm{M}$. Phase 3 Study of Reslizumab in $\mathrm{Pa}$ tients With Poorly Controlled Asthma: Effects Across a Broad Range of Eosinophil Counts. Chest. 2016 Oct;150(4):799-810.

71 FitzGerald JM, Bleecker ER, Nair P, Korn S, Ohta K, Lommatzsch M, et al.; CALIMA study investigators. Benralizumab, an antiinterleukin-5 receptor a monoclonal antibody, as add-on treatment for patients with severe, uncontrolled, eosinophilic asthma (CALIMA): a randomised, double-blind, placebo-controlled phase 3 trial. Lancet. 2016 Oct:388(10056):2128-41.

72 Nair P, Wenzel S, Rabe KF, Bourdin A, Lugogo NL, Kuna P, et al.; ZONDA Trial Investigators. Oral Glucocorticoid-Sparing Effect of Benralizumab in Severe Asthma. N Engl J Med. 2017 Jun;376(25):2448-58.

73 Bel EH, Wenzel SE, Thompson PJ, Prazma CM, Keene ON, Yancey SW, et al.; SIRIUS Investigators. Oral glucocorticoid-sparing effect of mepolizumab in eosinophilic asthma. N Engl J Med. 2014 Sep;371(13):1189-97.

74 FitzGerald JM, Bleecker ER, Menzies-Gow A, Zangrilli JG, Hirsch I, Metcalfe P, et al. Predictors of enhanced response with benralizumab for patients with severe asthma: pooled analysis of the SIROCCO and CALIMA studies. Lancet Respir Med. 2018 Jan; 6(1):51-64.

75 Khurana S, Brusselle GG, Bel EH, FitzGerald JM, Masoli M, Korn S, et al. Long-term Safety and Clinical Benefit of Mepolizumab in $\mathrm{Pa}$ tients With the Most Severe Eosinophilic Asthma: the COSMEX Study. Clin Ther. 2019 Oct;41(10):2041-2056.e5. 
76 FitzGerald JM, Bleecker ER, Bourdin A, Busse WW, Ferguson GT, Brooks L, et al. Two-year integrated efficacy and safety analysis of benralizumab in severe asthma. J Asthma Allergy. 2019 Dec;12:401-13.

77 Gleich GJ, Klion AD, Lee JJ, Weller PF. The consequences of not having eosinophils. Allergy. 2013 Jul;68(7):829-35.

78 Brusselle G, Germinaro M, Weiss S, Zangrilli $\mathrm{J}$. Reslizumab in patients with inadequately controlled late-onset asthma and elevated blood eosinophils. Pulm Pharmacol Ther. 2017 Apr;43:39-45.

79 Wechsler ME, Akuthota P, Jayne D, Khoury P, Klion A, Langford CA, et al.; EGPA Mepolizumab Study Team. Mepolizumab or Placebo for Eosinophilic Granulomatosis with Polyangiitis. N Engl J Med. 2017 May;376(20): 1921-32.

80 Kuang FL, Legrand F, Makiya M, Ware J, Wetzler L, Brown T, et al. Benralizumab for PDGFRA-Negative Hypereosinophilic Syndrome. N Engl J Med. 2019 Apr;380(14): 1336-46.

81 Bachert C, Sousa AR, Lund VJ, Scadding GK, Gevaert P, Nasser S, et al. Reduced need for surgery in severe nasal polyposis with mepolizumab: randomized trial. J Allergy Clin Immunol. 2017 Oct;140(4):1024-1031.e14.

82 Maes T, Joos GF, Brusselle GG. Targeting interleukin-4 in asthma: lost in translation? Am J Respir Cell Mol Biol. 2012 Sep;47(3):261-70.

83 Panettieri RA Jr, Sjöbring U, Péterffy A, Wessman P, Bowen K, Piper E, et al. Tralokinumab for severe, uncontrolled asthma (STRATOS 1 and STRATOS 2): two randomised, double-blind, placebo-controlled, phase 3 clinical trials. Lancet Respir Med. 2018 Jul;6(7):511-25.

84 Hanania NA, Korenblat P, Chapman KR, Bateman ED, Kopecky P, Paggiaro P, et al. Efficacy and safety of lebrikizumab in patients with uncontrolled asthma (LAVOLTA I and LAVOLTA II): replicate, phase 3, randomised, double-blind, placebo-controlled trials. Lancet Respir Med. 2016 Oct;4(10): 781-96.

85 Wenzel S, Castro M, Corren J, Maspero J, Wang L, Zhang B, et al. Dupilumab efficacy and safety in adults with uncontrolled persistent asthma despite use of medium-to-highdose inhaled corticosteroids plus a long-acting $\beta 2$ agonist: a randomised double-blind placebo-controlled pivotal phase $2 \mathrm{~b}$ doseranging trial. Lancet. 2016 Jul;388(10039):3144.
86 Castro M, Corren J, Pavord ID, Maspero J, Wenzel S, Rabe KF, et al. Dupilumab Efficacy and Safety in Moderate-to-Severe Uncontrolled Asthma. N Engl J Med. 2018 Jun; 378(26):2486-96

87 Rabe KF, Nair P, Brusselle G, Maspero JF, Castro M, Sher L, et al. Efficacy and Safety of Dupilumab in Glucocorticoid-Dependent Severe Asthma. N Engl J Med. 2018 Jun;378(26): 2475-85.

88 Thaçi D, Simpson EL, Beck LA, Bieber T, Blauvelt A, Papp K, et al. Efficacy and safety of dupilumab in adults with moderate-to-severe atopic dermatitis inadequately controlled by topical treatments: a randomised, placebo-controlled, dose-ranging phase $2 \mathrm{~b}$ trial. Lancet. 2016 Jan;387(10013):40-52.

89 Buhl R, Humbert M, Bjermer L, Chanez P, Heaney LG, Pavord I, et al.; expert group of the European Consensus Meeting for Severe Eosinophilic Asthma. Severe eosinophilic asthma: a roadmap to consensus. Eur Respir J. 2017 May;49(5):49.

90 Roan F, Obata-Ninomiya K, Ziegler SF. Epithelial cell-derived cytokines: more than just signaling the alarm. J Clin Invest. 2019 Apr; 129(4):1441-51.

91 Kumar RK, Foster PS, Rosenberg HF. Respiratory viral infection, epithelial cytokines, and innate lymphoid cells in asthma exacerbations. J Leukoc Biol. 2014 Sep;96(3):391-6.

92 Hammad H, Lambrecht BN. Barrier Epithelial Cells and the Control of Type 2 Immunity. Immunity. 2015 Jul;43(1):29-40.

93 Corren J, Parnes JR, Wang L, Mo M, Roseti SL, Griffiths JM, et al. Tezepelumab in Adults with Uncontrolled Asthma. N Engl J Med. 2017 Sep;377(10):936-46.

94 Londei M, Marquette-Hamoudi A, Phenis K, Pinkstaff J, Sacco N, Pavord ID. Single-dose phase $2 \mathrm{a}$ trial of etokimab (anti-IL-33) in severe eosinophilic asthma. Abstract No. LBOA1714. Presented at the EAACI Meeting 2019 June 5; Lisbon, Portugal.

95 Chen YL, Gutowska-Owsiak D, Hardman CS, Westmoreland M, MacKenzie T, Cifuentes L, et al. Proof-of-concept clinical trial of etokimab shows a key role for IL-33 in atopic dermatitis pathogenesis. Sci Transl Med. 2019 Oct;11(515): 11

96 Chinthrajah S, Cao S, Liu C, Lyu SC, Sindher $\mathrm{SB}$, Long A, et al. Phase 2a randomized, placebo-controlled study of anti-IL-33 in peanut allergy. JCI Insight. 2019 Nov;4(22):4.
97 Krug N, Hohlfeld JM, Kirsten AM, Kornmann O, Beeh KM, Kappeler D, et al. Allergen-induced asthmatic responses modified by a GATA3-specific DNAzyme. N Engl J Med. 2015 May;372(21):1987-95.

98 Farne HA, Johnston SL. Immune mechanisms of respiratory viral infections in asthma. Curr Opin Immunol. 2017 Oct;48:31-7.

99 McCrae C, Olsson M, Aurell M, et al. Ondemand inhaled interferon-beta 1 a for the prevention of severe asthma exacerbations: results of the INEXAS phase 2a study. Am J Respir Crit Care Med. 2018;197:A6165.

100 Djukanović R, Harrison T, Johnston SL, Gabbay F, Wark P, Thomson NC, et al.; INTERCIA Study Group. The effect of inhaled IFN- $\beta$ on worsening of asthma symptoms caused by viral infections. A randomized trial. Am J Respir Crit Care Med. 2014 Jul; 190(2):145-54.

101 Bjermer L, Abbott-Banner K, Newman K. Efficacy and safety of a first-in-class inhaled PDE3/4 inhibitor (ensifentrine) vs salbutamol in asthma. Pulm Pharmacol Ther. 2019 Oct; $58: 101814$

102 Cazzola M, Calzetta L, Rogliani P, Matera MG. Ensifentrine (RPL554): an investigational PDE3/4 inhibitor for the treatment of COPD. Expert Opin Investig Drugs. 2019 Oct;28(10):827-33.

103 Kirjavainen PV, Karvonen AM, Adams RI, Täubel M, Roponen M, Tuoresmäki $\mathrm{P}$, et al. Farm-like indoor microbiota in non-farm homes protects children from asthma development. Nat Med. 2019 Jul;25(7):1089-95.

104 Fitzgibbon G, Mills KH. The microbiota and immune-mediated diseases: opportunities for therapeutic intervention. Eur J Immunol. 2020 Jan;eji.201948322.

105 Borbet TC, Zhang X, Müller A, Blaser MJ. The role of the changing human microbiome in the asthma pandemic. J Allergy Clin Immunol. 2019 Dec;144(6):1457-66.

106 Jevnikar Z, Östling J, Ax E, Calvén J, Thörn $\mathrm{K}$, Israelsson E, et al.; Unbiased Biomarkers in Prediction of Respiratory Disease Outcomes Study Group. Epithelial IL-6 transsignaling defines a new asthma phenotype with increased airway inflammation. J Allergy Clin Immunol. 2019 Feb;143(2):577-90.

107 Östling J, van Geest M, Schofield JP, Jevnikar Z, Wilson S, Ward J, et al.; U-BIOPRED Study Group. IL-17-high asthma with features of a psoriasis immunophenotype. J Allergy Clin Immunol. 2019 Nov;144(5): 1198-213. 